\title{
ANALIZA ORGANIZACJI PRZESTRZENNEJ BIBLIOTEKI Z PUNKTU WIDZENIA KULTURY ORGANIZACYJNEJ NA PRZYKŁADZIE GMACHU BIBLIOTEKI UNIWERSYTECKIEJ IM. JERZEGO GIEDROYCIA I KSIĄŻNICY PODLASKIEJ IM. ŁUKASZA GÓRNICKIEGO
}

\author{
Library Space as Seen through the Lens of Organisational \\ Culture: The Building OF The University Library in BiakystoK \\ and Książnica Podlaska
}

\begin{abstract}
Abstrakt
Celem artykułu jest przedstawienie oceny dawnego gmachu Biblioteki Uniwersyteckiej im. Jerzego Giedroycia, obecnie zajmowanego przez Książnicę Podlaską im. Łukasza Górnickiego, z użyciem innowacyjnej metodologii badania fizycznej przestrzeni gmachów bibliotecznych w oparciu o teoretyczny model analizy kultury organizacyjnej oparty o model wymiarów kultury zaproponowany przez Geerta Hofstedego. W badaniu zastosowano metodę obserwacji uczestniczącej, w której badacz analizuje organizację przestrzenną biblioteki z punktu widzenia czytelnika, w oparciu o formularz dotyczący aspektów organizacji przestrzennej związanych z wybranymi wymiarami kultury z modelu 6D Hofstedego. Badanie wykazało, że model kultury organizacyjnej omawianych bibliotek wyłaniający się z organizacji przestrzennej ich gmachu, odbiega od zaleceń literatury przedmiotu. Co więcej, po przejęciu gmachu przez Książnicę Podlaską, skopiowano wiele chybionych rozwiązań przestrzennych stosowanych wcześniej w Bibliotece Uniwersyteckiej, mimo iż te biblioteki pełnią zasadniczo odmienne funkcje.
\end{abstract}

Słowa kluczowe: przestrzeń biblioteczna, organizacja przestrzenna, architektura bibliotek, budownictwo biblioteczne, kultura organizacyjna. 


\begin{abstract}
The aim of the article is to present an assessment of the former building of Biblioteka Uniwersytecka im. Jerzego Giedroycia, which is currently occupied by Książnica Podlaska im. Łukasza Górnickiego using an innovative methodology of analysing the physical space of library buildings in relation to a theoretical model of organisational culture based on Geert Hofstede's six-dimensional model of culture. Research was conducted using the hidden agent method, whereby the researcher posed as a reader to observe library space and analyse it on the basis of an observation form detailing aspects of spatial organisation related to selected dimensions of culture from Hofstede's 6D model. The research indicates that the image of organisational culture projected by the space of the library building in question diverges from what is proposed in subject literature. Moreover, the spatial organisation of Książnica Podlaska copies many of the solutions adopted by the building's previous occupant, even though the role of the two libraries is markedly different.
\end{abstract}

Keywords: library space, spatial organisation, library architecture, library buildings, organisational culture.

\title{
Wstęp
}

Przestrzeń biblioteczna i jej wykorzystanie to istotne zagadnienia dla funkcjonowania bibliotek. Organizacja przestrzenna wpływa na wiele aspektów działalności biblioteki, od kwestii organizacyjnych i technicznych, po kulturę organizacyjną i wizerunek biblioteki. W ostatnich dekadach w Polsce powstało wiele nowych gmachów bibliotecznych, dokonuje się też remontów i rewitalizacji w siedzibach już istniejących. Problematyka organizacji przestrzennej bibliotek stała się zatem istotnym obszarem zainteresowania badaczy. Jednocześnie, mimo iż koncepcje kultury organizacyjnej przeniknęły w ostatnich latach do świadomości środowiska bibliotekarskiego, niewiele jest publikacji łączących te dwa zagadnienia, szczególnie w bardziej ogólnym i kompleksowym wymiarze.

Związkom między organizacją przestrzenną biblioteki a jej kulturą organizacyjną Elżbieta Barbara Zybert poświęciła rozdział w książce Kultura organizacyjna $w$ bibliotekach ${ }^{1}$. Autorka podkreśla, że budynek

1 E. B. Zybert: Organizacja przestrzeni bibliotecznej jako element kultury organizacyjnej.

W: E. B. Zybert: Kultura organizacyjna w bibliotekach. Warszawa 2004, s. 163-177. 
i wyposażenie biblioteki można uznać za artefakty, czyli materialne przejawy jej kultury organizacyjnej. Organizacja przestrzenna odgrywa szczególną rolę w kreowaniu przyjaznej, otwartej atmosfery istotnej w bibliotece przyjmującej postawę "prokliencką". Jako najważniejszą cechę „przyjaznej” przestrzeni bibliotecznej E. B. Zybert wymienia łatwość poruszania się po bibliotece (wynikającą przede wszystkim z intuicyjnej, logicznej i czytelniej organizacji wnętrza). Jedną z najważniejszych cech przyjaznej przestrzeni bibliotecznej wydaje się też „otwartość wizualna”, a więc taka organizacja wnętrza, która pozwala czytelnikowi widzieć jak najwięcej wnętrza biblioteki - zwiększa to wspomnianą łatwość poruszania się po bibliotece i pomaga w pokonaniu barier psychologicznych, związanych z korzystaniem z biblioteki. Ta otwartość, zarówno wizualna, jak i fizyczna, jest najczęściej wymienianym aspektem dobrej przestrzeni bibliotecznej. Istotny dla stworzenia przyjaznej atmosfery jest też wystrój wnętrza. Trudno jednoznacznie określić, co stanowi o przyjazności wystroju, ale E. B. Zybert wymienia tu takie cechy, jak unikanie zarówno przepychu, jak i monotonii oraz wprowadzenie skromnych elementów zdobniczych (obrazy, kwiaty, sztuka użytkowa). Przyjazności biblioteki służy też wolny dostęp i swoboda kontaktów między czytelnikiem a bibliotekarzem.

Kilka artykułów na ten temat pojawia się w tomie Kultura organizacyjna $w$ bibliotece ${ }^{2}$, ale $\mathrm{w}$ niewielkim stopniu odwołują się one do zagadnień kultury organizacyjnej. W zawartym w tym tomie artykule Agnieszka Bogusz zaznacza, że podstawę kultury organizacyjnej „stanowi już projekt architektoniczny budynku i organizacja pomieszczeńn”. Autorka nie rozwija jednak dalej tego tematu, nie wyjaśnia, jak organizacja przestrzenna wiąże się z kulturą organizacyjną, skupiając się na innych aspektach kultury organizacyjnej.

Kolejny artykuł, autorstwa Radosława Gazińskiego i Mirosławy Różyckiej ${ }^{4}$, dotyczy już bezpośrednio organizacji przestrzennej bibliotek (w adaptowanych budynkach historycznych), jednak w kwestii kultury organizacyjnej, również ogranicza się do pojedynczego stwierdzenia. Autorzy wyjaśniają, że organizacja przestrzenna biblioteki jest istotnym

2 Kultura organizacyjna w bibliotece. Red. H. Brzezińska-Stec. Białystok 2008.

3 A. Bogusz: Image nowo powstającej biblioteki w oparciu o kulture organizacyjna na przykładzie Biblioteki Politechniki Krakowskiej. W: Kultura organizacyjna w bibliotece, dz. cyt., s. 361-373.

4 R. Gaziński, M. Różycka: Adaptacja obiektów historycznych na potrzeby biblioteki naukowej na przykładzie Biblioteki Głównej Uniwersytetu Szczecińskiego. W: Kultura organizacyjna w bibliotece, dz. cyt., s. 413-426. 
elementem jej kultury organizacyjnej, ponieważ „wpływa [...] na lepszą lub gorszą obsługę użytkownika"5.

Autorka innego artykułu zawartego w tym samym tomie, Lidia Szczygłowska ${ }^{6}$, podkreśla, że „tradycyjna kultura organizacyjna biblioteki, kładąca nacisk na stabilność, sztywne zasady, reguły i kontrolę"7 kontrastuje z potrzebami czytelników nowoczesnej biblioteki akademickiej. Podobnie Maria Pawłowska w swoim artykule wskazuje, że „kultura organizacyjna nowoczesnej biblioteki jest skierowana na użytkownika" ${ }^{\text {i }}$ że powinno to znaleźć odzwierciedlenie w otwartym planowaniu wnętrz. M. Pawłowska podkreśla też znaczenie aranżacji i wyposażenia wnętrz biblioteki jako artefaktów fizycznych kultury organizacyjnej.

Ukazały się też dwa artykuły autora niniejszej pracy, wiążące architekturę $\mathrm{i}$ organizację przestrzenną bibliotek $\mathrm{z}$ aspektami kultury narodowej. W pierwszym $\mathrm{z}$ nich autor omawia potencjalny związek między różnymi wartościami, tzw. wymiarów kultury zaproponowanych przez Geerta Hofstedego, a różnymi rozwiązaniami stosowanymi w architekturze i organizacji przestrzennej bibliotek ${ }^{9}$. W kolejnym podejmuje próbę podobnego porównania dla wymiarów kultury zaproponowanych przez Fonsa Trompenaarsa i Charlesa Hampden-Turnera ${ }^{10}$. W swojej pracy doktorskiej autor zajmuje się tą tematyką w szerszym zakresie: zawiera ona szczegółowe omówienie modelu 6D Hofstedego w kontekście działalności i organizacji przestrzennej bibliotek oraz badania przestrzeni polskich i niemieckich bibliotek akademickich oparte na tym modelu ${ }^{11}$. Opracowane na potrzeby doktoratu narzędzie badawcze autor wykorzystuje także w tej pracy. Częściowe wyniki badań przeprowadzonych na potrzeby rozprawy

5 Tamże.

6 L. Szczygłowska: Nowa biblioteka - nowa przestrzeń - nowe możliwości - nowe wyzwania. W: Kultura organizacyjna w bibliotece, dz. cyt., s. 457-474.

7 Tamże.

8 M. Pawłowska: Wpływ architektury i aranżacji przestrzennej bibliotek na jej kulture organizacyjna. W: Kultura organizacyjna $w$ bibliotece, dz. cyt., s. 440-456.

9 M. Pędich: Biblioteka w pięciu wymiarach. W: Kultura organizacyjna $w$ bibliotece, dz. cyt., s. 427-439.

10 M. Pędich: Siedem wymiarów biblioteki. W: Język a komunikacja 25: Słowo w dialogu międzykulturowym. Red. W. Chłopicki, M. Jodłowiec. Kraków 2010, s. 47-53.

11 Kultura narodowa i organizacyjna w przestrzeni bibliotek. Studium porównawcze na przykładzie bibliotek akademickich w Polsce i Niemczech oddanych do użytku po 1989 r. Toruń 2017. 
doktorskiej autor opublikował w "Zarządzaniu Biblioteką...”12. Kolejny artykuł przedstawiający dalsze wyniki badań oczekuje na publikację $\mathrm{w}$ tymże czasopiśmie ${ }^{13}$.

Polskie piśmiennictwo odnoszące się do związków kultury organizacyjnej z organizacją przestrzenną i architekturą bibliotek jest skromne. Co więcej, nieliczne pozycje dotyczące tego tematu zawierają przede wszystkim praktyczne porady, niepowiązane z teorią kultury organizacyjnej. Wydaje się, że takie ujęcie sprawy - spojrzenie na organizację przestrzenną bibliotek przez pryzmat jednej lub kilku teorii kultury - mogłoby być szczególnie wartościowe, gdyż pozwoliłoby zarówno na poszerzenie, jak i usystematyzowanie wiedzy o tej tematyce.

\section{Narzędzie badawcze}

Przygotowując rozprawę doktorską autor przeprowadził badania w wybranych bibliotekach w Polsce i w Niemczech, posługując się autorskim narzędziem badawczym, które wykorzystuje również na potrzeby tej pracy. Ponieważ obiektem zainteresowania autora jest budynek biblioteki, jako artefakt kultury organizacyjnej, zastosowanie typowych w badaniach nad kulturą organizacyjną metod ankiety i wywiadu, nie było uzasadnione. Zamiast tego drugą zastosowaną metodą była obserwacja uczestnicząca, prowadzona anonimowo, $\mathrm{z}$ punktu widzenia czytelnika (elementy tzw. metody hidden agent) i oparta o ustrukturyzowany arkusz obserwacji. Zastosowane narzędzie jest listą zamkniętych pytań dotyczących różnych aspektów organizacji przestrzennej biblioteki, które mogą mieć związek z jej kulturą organizacyjną. Odpowiedzi na te pytania pozwalają na stworzenie swego rodzaju „profilu kulturowego” budynku biblioteki. Arkusz stał się punktem wyjścia do pogłębionej obserwacji każdego budynku z możliwością wskazania na szczególne indywidualne cechy i uwarunkowania.

Arkusz obserwacji oparty jest na modelu sześciu wymiarów kultury zaproponowanych przez Geerta Hofstedego (tzw. model 6D). Podobnie jak wielu innych badaczy zajmujących się międzykulturowością, Hofstede poświęca dużo uwagi problemom międzynarodowej przedsiębiorczości.

12 Individualism and Collectivism in Library Architecture. An Analysis of Selected New Library Buildings in the Former East Germany. „Zarządzanie Biblioteką: Library Management" Nr 1(10) (2018), s. 118-142.

13 Uncertainty Avoidance in Library Architecture. An Analysis of Selected New Library Buildings in the Former East Germany. „Zarządzanie Biblioteką: Library Management”. 
Jednakże jego model wymiarów jest bardziej wszechstronny, dotykając wszystkich aspektów życia społecznego - od wychowania dzieci, poprzez edukację, po stosunki w pracy, przedsiębiorczość i politykę. Hofstede nie tylko wskazuje na istnienie tych aspektów wymiarów kultury, ale przedstawia je w sposób szczegółowy i wyczerpujący. Z tego względu model Hofstedego lepiej niż inne nadaje się do studiów nad dziedziną, której badacze międzykulturowości nie poświęcają zwykle uwagi. Dowodem na to jest wykorzystanie modelu Hofstedego w badaniach nad edukacją ${ }^{14}$ (która ma wiele cech wspólnych z działalnością biblioteczną) i bibliotekoznawstwem ${ }^{15}$. Ważne jest też, że Hofstede, w odróżnieniu od wielu (szczególnie wcześniejszych) badaczy, nie oparł swojego modelu na obserwacjach i rozważaniach teoretycznych ${ }^{16}$, ale na wnikliwej analizie obszernych badań kwestionariuszowych. Dodatkową zaletą tego modelu jest jego przejrzystość oraz możliwość wykorzystania wartości numerycznych wymiarów, wynikających z badań różnych kultur narodowych.

Choć model sześciu wymiarów stworzono do opisywania kultur narodowych, to można za ich pomocą opisywać również kultury organizacyjne. Przykład takiego wykorzystania można znaleźć m.in. w pracy Bożeny Jaskowskiej: Jak badać kulturę organizacyjna w bibliotece akademickiej: ${ }^{17}$. Badaczka odwołuje się do wymiarów: dystansu władzy, indywidualizmu-kolektywizmu oraz unikania niepewności, na których koncentruje się również przedstawiona w tej pracy metoda badawcza.

Koncepcja badań jest związana z przekonaniem, że jeżeli kultura przenika wszelkie aspekty ludzkiej działalności, należy założyć, że znajduje ona odbicie także w działalności bibliotecznej. Potwierdzają to liczne prace dotyczących kultury narodowej i organizacyjnej. Spośród różnych aspektów

14 Np. W. Littlewood: Students' attitudes to classroom English learning. „Language Teaching Research" 2001, 5(1), s. 3-28; A. Dzięcioł: The Communicative Approach in Foreign Language Teaching and the Negative Stereotype of the Polish Student. W: Us and Them - Them and Us. Eds. A. Gonerko-Frej et al. Aachen 2011, s. 605-620.

15 Np. B. Jaskowska: Jak badać kulturę organizacyjna w bibliotece akademickiej? W: Kultura organizacyjna $w$ bibliotece, dz. cyt., s. 25-42; M. Pędich: Biblioteka w pięciu wymiarach. W: Kultura organizacyjna w bibliotece, dz. cyt., s. 427-439.

16 Dla porównania, badania prowadzone przez Fonsa Trompenaarsa i Charlesa Hampden-Turnera (Siedem wymiarów kultury. Kraków 2002) nie tylko dotyczyły znacznie mniejszych grup respondentów, ale były prowadzone po sformułowaniu teorii, w celu jej sprawdzenia, czy też ustalenia jaką pozycję różne kraje zajmują na skali poszczególnych wymiarów. Wielu innych badaczy (np. skądinąd niezwykle wartościowy i wpływowy Edward T. Hall) w ogóle nie przedstawia badań ilościowych.

17 B. Jaskowska: Jak badać kulturę organizacyjną..., dz. cyt. 
funkcjonowania bibliotek, które mogą świadczyć o jej kulturze organizacyjnej lub tę kulturę kształtować, w tej pracy za obiekt badań wybrano jej organizację przestrzenną ${ }^{18}$.

W instytucji usługowej, jaką jest biblioteka, najważniejszą rolę odgrywają relacje instytucji z użytkownikiem. Wskazują na to dokumenty określające tzw. misję wielu bibliotek. Na przykład w opisie misji Biblioteki Uniwersyteckiej w Poznaniu, podkreślany jest jej przyjazny charakter i fachowa obsługa czytelników ${ }^{19}$. Jako cele strategiczne Biblioteki Uniwersyteckiej im. J. Giedroycia podawane jest „zapewnienie użytkownikom łatwego dostępu do zbiorów” i „kreowanie dobrego wizerunku biblioteki w środowisku”20. W misji Biblioteki Uniwersyteckiej we Wrocławiu podkreślono chęć zaspokajania oczekiwań i potrzeb użytkowników ${ }^{21}$. Ponadto to w strefie czytelnika najbardziej widoczna jest wyjątkowość biblioteki jako instytucji. $\mathrm{Na}$ zapleczu, tam gdzie odbywa się gromadzenie i opracowanie, biblioteka jest pod wieloma względami podobna do innych organizacji, takich jak: archiwa, biura, urzędy. Tam toczy się tzw. drugie życie placówki - niewidoczne dla klientów. Natomiast w strefie użytkownika wykonywane są zadania i świadczone usługi, które najbardziej odróżniają bibliotekę od innych instytucji. Dlatego też budynek biblioteki jest w przedstawionych tu badaniach opisywany z punktu widzenia czytelnika - uwzględniono te aspekty organizacji przestrzennej budynku biblioteki, których czytelnik może doświadczyć. Takie ograniczenie ma też wymiar praktyczny. Badaczowi chcącemu obserwować budynek biblioteki od zaplecza trudno uniknąć bycia w jakimś stopniu „oprowadzanym”. Wcielając się w rolę czytelnika można uzyskać bardziej autentyczne doświadczenie obcowania z biblioteką.

Stworzony przez autora na potrzeby badań formularz obserwacji składa się z 25 pytań związanych z różnymi aspektami organizacji przestrzennej biblioteki. Podstawowym kluczem doboru pytań była analiza teorii wymiarów kultury Hofstedego pod kątem jej związków z różnymi aspektami funkcjonowania bibliotek. Należy też zaznaczyć, że wiele z uwzględnionych

18 Szerszą analizę związków różnych aspektów kultury (wedle modelu 6D G. Hofstedego) autor przedstawił w artykule: M. Pędich: Biblioteka w pięciu wymiarach. W: Kultura organizacyjna w bibliotece, dz. cyt., s. 427-439.

19 Biblioteka Uniwersytecka w Poznaniu. Misja Biblioteki Uniwersyteckiej. Tryb dostępu: http://lib.amu.edu.pl/misja-biblioteki/ [24 lutego 2017].

20 Biblioteka Uniwersytecka im. Jerzego Giedroycia. Misja. Tryb dostępu: https://bg.uwb. edu.pl/bu/o-bibliotece/przewodnik-po-bibliotece/826-misja [24 lutego 2017].

21 Biblioteka Uniwersytecka we Wrocławiu. O Bibliotece - Misja Biblioteki. Tryb dostępu: http://www.bu.uni.wroc.pl/o-bibliotece/organizacja-biblioteki-misja [24 lutego 2017]. 
$\mathrm{w}$ formularzu cech przestrzeni bibliotecznej należy do najważniejszych aspektów architektury i organizacji przestrzennej biblioteki. Każdemu z pytań przypisano kilka możliwych odpowiedzi, które podczas obserwacji uzupełniane były szczegółowymi notatkami. Odpowiedzi na poszczególne pytania można przypisać do różnych wymiarów kultury. Podzielono je na trzy grupy związane z trzema pierwszymi wymiarami Hofstedego: indywidualizmem, unikaniem niepewności i dystansem władzy, co pozwala na określenie tendencji, jakim sprzyja organizacja przestrzenna poszczególnych bibliotek. Szczegółowe omówienie struktury formularza obserwacji, jak i jego podstaw teoretycznych znalazło się w rozprawie doktorskiej autora. Arkusz obserwacji zawiera następujące pytania:

\section{Indywidualizm}

1. Czy w bibliotece jest wolny dostęp do półek?

2. W jaki sposób biblioteka podzielona jest na działy?

3. Czy w bibliotece znajdują się specjalne pomieszczenia do pracy grupowej?

4. Czy w bibliotece są osobne pomieszczenia (czytelnie, pracownie) dla pracowników naukowych?

5. Czy w bibliotece są obszary/pomieszczenia przeznaczone na kontakty towarzyskie czytelników?

6. Czy w bibliotece są urządzenia do samodzielnego wypożyczania i zwrotu książek?

7. Czy bardziej są wyeksponowane samoobsługowe stanowiska komputerowe, czy informacyjne bibliotekarzy?

8. Jak duże jest zróżnicowanie wnętrza?

9. Gdzie umieszczono stanowiska komputerowe dla czytelników?

10. W jakim stopniu budynek biblioteki podporządkowany jest potrzebom uczelni?

11. Czy można powiedzieć, że budynek ma tzw. Wow factor ${ }^{22}$

\section{Unikanie niepewności}

1. Czy budynek jest elastyczny?

22 Koncepcję Wow Factor omawia szczegółowo w swoim artykule Andrew McDonald: The Ten Commandments revisited: the Qualities of Good Library Space. „Liber Quarterly" Vol. 16, nr 2 (2006). Tryb dostępu: http://liber.library.uu.nl/index.php/lq/article/ view/7840/8010 [24 lutego 2017]. 
2. Co znajduje się w „centrum grawitacji” budynku biblioteki? Czytelnik, bibliotekarz, czy książka (magazyn)?

3. Czy biblioteka zachowuje podział na strefę czytelnika i bibliotekarza?

4. W jaki sposób zorganizowane jest wnętrze strefy czytelnika w bibliotece?

5. W jaki sposób zapewniono czytelnikom możliwość korzystania z Internetu?

6. W jaki sposób czytelnicy są nadzorowani w bibliotece?

7. Czy swoboda poruszania się czytelnika w bibliotece jest ograniczona?

8. Jakie rodzaje oznaczeń są najczęściej spotykane w budynku biblioteki?

\section{Dystans władzy}

1. Czy w bibliotece widoczne są symbole statusu bibliotekarza?

2. Czy biblioteka sprawia wrażenie otwartej i łatwo dostępnej?

3. W jakim stopniu budynek podporządkowany jest wymogom pracy biblioteki? Czy budynek biblioteki pełni funkcje wykraczające poza podstawowe zadania biblioteki?

4. Czy w budynku są kwiaty/zieleń?

5. Które określenia najlepiej określają styl i estetykę wyposażenia i wystroju budynku biblioteki: efektywność, nowoczesność, oryginalność, tradycja, bezpieczeństwo, wygoda, standaryzacja, powaga (tzw. styl „świątyni”), oszczędność, historia, pragmatyczny, przyjazny, bogaty, inne?

6. Ile drzwi musi minąć czytelnik zanim dotrze do pierwszego stanowiska bibliotekarza lub czytelni?

7. Jakie miejsca w bibliotece znajdują się najbliżej wejścia?

\section{Gmach Biblioteki Uniwersyteckiej i Książnicy Podlaskiej}

Analizę organizacji przestrzennej gmachu Biblioteki Uniwersyteckiej im. Jerzego Giedroycia w Białymstoku (BU) autor przeprowadził na potrzeby swojej rozprawy doktorskiej (była to jedna $\mathrm{z}$ omawianych $\mathrm{w}$ rozprawie polskich bibliotek akademickich). Po przejęciu gmachu przez Książnicę Podlaską autor przeprowadził jego ponowną analizę, z użyciem tego samego narzędzia badawczego. Głównym celem niniejszego artykułu jest porównanie wykorzystania tej samej przestrzeni, przez obie biblioteki, w oparciu o sprawdzone narzędzie badawcze i model teoretyczny. 
Budowę nowej siedziby Biblioteki Uniwersyteckiej im. Jerzego Giedroycia w Białymstoku rozpoczęto w 1999 r. i ukończono w 2005 r. Pod koniec 2014 r. budynek został sprzedany Urzędowi Marszałkowskiemu Województwa Podlaskiego i obecnie mieści się w nim Książnica Podlaska im. Łukasza Górnickiego (KP). Zlokalizowany w centrum miasta przy ul. M. Skłodowskiej-Curie gmach sąsiadował z ówczesnym budynkiem Rektoratu Uniwersytetu w Białymstoku (UwB). Warto podkreślić, że z punktu widzenia biblioteki publicznej jest to bardzo dobra lokalizacja - w centrum miasta, przy jednej z głównych ulic, naprzeciw parku i z przystankiem autobusowym tuż za drzwiami. Budynek ma siedem kondygnacji, w tym jedną podziemną, a jego powierzchnia użytkowa wynosi około 8 tys. $\mathrm{m}^{2}$. Przewidziano, że magazyny pomieszczą ponad 800 tys. woluminów. Przy tym należy zauważyć, że zbiory Biblioteki Uniwersyteckiej to niecałe 600 tys. woluminów, ale już zbiory Książnicy Podlaskiej liczą ponad milion woluminów.

\section{INDYWIDUALIZM}

W budynku Biblioteki Uniwersyteckiej zaplanowano spory obszar wolnego dostępu, ale zajmował on tylko dwie z sześciu kondygnacji. Co więcej, ponieważ biblioteka $\mathrm{w}$ starej siedzibie miała system magazynowy, przenoszenie zbiorów do wolnego dostępu następowało stopniowo i można powiedzieć, że nigdy nie osiągnął on dominującej roli w organizacji biblioteki.

Książnica Podlaska w zasadzie zrezygnowała z wolnego dostępu, prawdopodobnie ze względu na wielkość zbiorów, aczkolwiek na pierwszym piętrze przy wypożyczalni znajduje się niewielka strefa wolnego dostępu ze zbiorami literatury popularnej i naukowej, a w czytelni ogólnej obok księgozbioru podręcznego umieszczono w wolnym dostępie czasopisma.

Najbardziej widoczną formą podziału zbiorów w BU był od początku podział formalny - wydzielono Czytelnię Czasopism i Oddział Zbiorów Specjalnych, a zbiory książkowe podzielono między magazyn zamknięty i strefę wolnego dostępu. Ze względów treściowych wydzielono zbiory Oddziału Informacji Naukowej oraz tzw. Kolekcję Humanistyczną, ale tylko te pierwsze były wyraźnie wydzielone w przestrzeni biblioteki. Z kolei w czytelni ogólnej KP na drugim piętrze umieszczono księgozbiór podręczny książek i czasopism, zaś na piętrze pierwszym przy wypożyczalni zorganizowano niewielką strefą wolnego dostępu z wydzielonymi zbiorami literatury popularnej i naukowej; przy czym księgozbiór podręczny zawiera także audiobooki. Nie ma też osobnej czytelni czasopism. Głównym 
kryterium podziału tych zbiorów, które są dostępne dla czytelników, wydaje się więc być kryterium tematyczne.

W budynku Biblioteki Uniwersyteckiej nie było specjalnych pomieszczeń do pracy grupowej, nie ma ich również obecnie. Nie było też osobnej czytelni ani innych pomieszczeń dla pracowników naukowych, aczkolwiek mieli oni pierwszeństwo w dostępie do kabin pracy indywidualnej, których obecnie nie ma.

W gmachu Biblioteki Uniwersyteckiej zaplanowano miejsce na bar, ale umieszczono je na ostatniej kondygnacji, co prawdopodobnie było jedną z przyczyn jego nieopłacalności i ostatecznie zamknięcia. Po jego likwidacji początkowo nadal była to przestrzeń „wypoczynkowa” dostępna dla czytelników, później zaadaptowano ją na salę Senatu UwB. W holu na parterze stało kilka stolików dla czytelników, ale były one rzadko wykorzystywane, ponieważ na tej kondygnacji znajdowała się tylko szatnia i sala wystawowa, więc użytkownicy spędzali tu mało czasu. Kanapy i stoliki umieszczono także w przedsionkach na wyższych piętrach. Po zmianie właściciela nic się w tej kwestii nie zmieniło. Nadal nie ma kawiarni czy baru, a przestrzeń na parterze i ostatnim piętrze wykorzystywana jest w niewielkim stopniu.

Większość stanowisk komputerowych dla czytelników zgromadzono w holu katalogowym i w pracowni komputerowej, trzy komputery udostępniano w Oddziale Informacji Naukowej. Na pierwszym piętrze wypożyczalnię umieszczono bliżej wejścia niż salę katalogów, w której zgromadzono stanowiska komputerowe. W pozostałych częściach Biblioteki stanowisk komputerowych nie było, albo były mniej wyeksponowane niż stanowiska bibliotekarzy. Wyjątek stanowił Oddział Informacji Naukowej, w którym komputery umieszczono przy wejściu, a stanowisko bibliotekarza w głębi czytelni. Z urządzeń do samodzielnego wypożyczania/zwrotu biblioteka miała tylko tzw. bibliobox (zewnętrzną wrzutnię do zwrotu książek). Obecnie w Książnicy Podlaskiej wszystkie nieliczne stanowiska komputerowe umieszczono w Informatorium, a w Wypożyczalni znajdują się terminale samoobsługowe.

Mimo zastosowania jednolitych mebli, zróżnicowanie wnętrza Biblioteki było dość duże, przede wszystkim ze względu na niejednolity układ przestrzeni na poszczególnych piętrach. Każda kondygnacja miała zupełnie inny plan i choć być może utrudniało to poruszanie się po Bibliotece, to zapobiegało monotonii. Książnica Podlaska dodatkowo wzbogaciła wyposażenie m.in. o wygodne kolorowe fotele. 
Można powiedzieć, że budynek bardzo silnie podporządkowano potrzebom Uczelni, ponieważ umieszczono w nim, obok sali konferencyjnej i wystawowej, salę obrad Senatu. Zlokalizowanie budynku biblioteki w centrum, przy przystanku autobusowym, wprawdzie obok budynku Rektoratu, ale $\mathrm{z}$ dala od budynków większości wydziałów, mogłoby być sposobem na „otwarcie się" na czytelnika z zewnątrz, w gmachu Biblioteki zastosowano jednak szereg rozwiązań przestrzennych mających zwiększyć dystans między biblioteką a mieszkańcami miasta (po przejęciu budynku przez Książnicę Podlaską zachowano, niestety, wszystkie te rozwiązania).

Najbardziej efektownym aspektem budynku jest piękny widok z czytelni na główną oś widokową parku pałacowego, a gmach jako całość robi z zewnątrz wrażenie niewyróżniającego się budynku biurowego.

Organizacja przestrzenna budynku Biblioteki Uniwersyteckiej i Książnicy Podlaskiej sugerowała i nadal sugeruje raczej kolektywizm niż indywidualizm, ale w nieznacznym stopniu. Była i jest więc dość odległa od zaleceń, jakie znaleźć możemy w literaturze przedmiotu. Choć po przejęciu budynku przez Książnicę Podlaską zrezygnowano w zasadzie z wolnego dostępu jako głównego trybu dostępu do zbiorów, udostępnienie niewielkich, ale popularnych zbiorów w wolnym dostępie robi pozytywne wrażenie na czytelniku.

\section{UNIKANIE NIEPEWNOŚCI}

Z technicznego punktu widzenia dawny budynek Biblioteki Uniwersyteckiej im. Jerzego Giedroycia w Białymstoku realizuje zasadę elastyczności - stropy mają jednolitą nośność, konstrukcję oparto na słupach, przestrzeń dzieląc głównie lekkimi, często szklanymi, ściankami działowymi (lub wcale); windy i klatkę schodową skupiono w centrum budynku. Jednocześnie budynek ma kilka cech, które tę elastyczność ograniczają. Ponieważ gmach otoczony jest wyższymi budynkami, tylko ściana frontowa jest przeszklona, a pozostałe ściany wyposażono w niewielkie okna, tak więc tylko część frontowa dobrze nadaje się na czytelnię. Niewielkie okna ma także piąta kondygnacja mieszcząca magazyn, do którego dodatkowo nie ma wejścia z ogólnodostępnej klatki schodowej i windy. Z kolei winda do przewozu książek nie dociera na parter, więc trudno byłoby przenieść tam wypożyczalnię czy czytelnie. Podobnie trudno byłoby na parterze umieścić bar czy kawiarnię, bo odpowiednia infrastruktura jest na ostatnim piętrze. Tak więc, mimo iż budynek jest elastyczny, to zmiana zastosowanego w nim układu przestrzennego wiązałaby się z licznymi problemami. 
Być może dlatego po przejęciu budynku przez Książnicę Podlaską nie wprowadzono znaczących zmian w jego organizacji przestrzennej.

W wielopiętrowych budynkach często trudno jest określić, co znajduje się w centrum grawitacji, a w przypadku gmachu dawnej BU utrudniał to też niejednolity układ poszczególnych pięter. Niemniej jednak, oś budynku stanowi ciąg komunikacji pionowej - klatka schodowa i winda, a na większości kondygnacji w najbardziej centralnej pozycji znajduje się jakiś hol lub czytelnia. Można więc zaryzykować stwierdzenie, że w centrum grawitacji znalazł się czytelnik. Natomiast po przejęciu budynku przez Książnicę Podlaską strefę czytelnika ograniczono do trzech dolnych kondygnacji, co sprawia, że za centrum grawitacji budynku trzeba jednak uznać magazyn.

Podział budynku na obszary o różnych funkcjach był wyraźny, chociaż nie zawsze przejrzysty. W budynku zachowano podział na strefę czytelnika i bibliotekarza, choć niezbyt zręcznie. Na większości pięter od frontu znajdowała się strefa czytelnika, a w tylnej części budynku bibliotekarza. Podział taki (mniej skuteczny niż przypisanie całych kondygnacji do jednej strefy) zastosowano najprawdopodobniej ze względu na gorsze oświetleniem tylnej części gmachu, stojącego w cieniu wyższych budynków. Oprócz tego dwie kondygnacje (piąte piętro i piwnica) były całkowicie niedostępne dla czytelników. Podział na ogół był dość jasny i nie było ryzyka przypadkowego wkroczenia do niewłaściwej strefy, chociaż np. na pierwszym piętrze, pomieszczenia Oddziału Informacji Naukowej oddzielono od holu katalogowego tylko przeszkloną ścianką działową, co wydawało się być źródłem pewnego dyskomfortu pracowników. Obecnie w większości zachowano ten sam układ.

W Bibliotece Uniwersyteckiej studentom udostępniano sieć eduroam, co dla docelowego czytelnika (studenta lub pracownika uczelni) oznaczało w zasadzie nieskrępowany dostęp do Internetu. Obecnie również udostępniono czytelnikom Internet zarówno przez sieć eduroam, jak i przez ogólnodostępną sieć bezprzewodową.

$\mathrm{Z}$ jednej strony, teoretycznie fizyczna swoboda poruszania się czytelnika nie była i nie jest nadmiernie ograniczana, z drugiej strony czytelnik odnosi zgoła inne wrażenie. Choć większość drzwi była i przynajmniej częściowo pozostaje otwarta, to jest ich po prostu za dużo, przez co wydaje się, że wszystko jest pozamykane. Obecnie, dodatkowo, większość budynku faktycznie jest niedostępna dla czytelników.

Choć były w budynku nieliczne miejsca, w których można było schować się przed czujnym wzrokiem bibliotekarza, w większości pomieszczeń biblioteki jego obecność (a więc i nadzór) była odczuwalna. Po przejęciu 
budynku przez Książnicę Podlaską zmniejszono liczbę stanowisk bibliotekarzy, co daje czytelnikowi większe poczucie prywatności (jednocześnie ich centralne położenie sprawia, że czytelnik nie czuje się zostawiony sam sobie). Wśród oznaczeń przeważały i nadal przeważają znaki informacyjne.

Podsumowując, organizacja przestrzenna budynku Biblioteki wskazywała i nadal wskazuje raczej na silne (choć nie skrajnie duże) unikanie niepewności, silniejsze niż sugerują zalecenia zawarte w literaturze przedmiotu, aczkolwiek Książnica Podlaska dokonała tu nieznacznych pozytywnych zmian.

Gmach Biblioteki miał (i nadal zachowuje) kilka wyraźnych symboli statusu instytucjonalnego, jak np. wyeksponowanie (poprzez umieszczenie na parterze blisko wejścia) sali wystawowej i gabinetów dyrekcji. Szczególnie, że nic nie skłania czytelnika do odwiedzenia wspomnianej sali wystawowej (wręcz przeciwnie, jej lokalizacja stwarza wrażenie, że przynależy ona do części administracyjnej budynku), co sugeruje, iż jej funkcja jest raczej prestiżowa niż kulturotwórcza czy edukacyjna. Nie było natomiast i nie ma $\mathrm{w}$ budynku zbyt wielu symboli statusu bibliotekarza $\mathrm{w}$ relacji z czytelnikiem - biurka były i są niewysokie i utylitarne, a nadzór bibliotekarzy odczuwalny, ale nie ostentacyjny. Dzięki wolnemu dostępowi w BU nie było też potrzeby częstego korzystania z pomocy pracowników.

\section{DYSTANS WEADZY}

Gmach biblioteki (niezależnie od właściciela) nie sprawia wrażenia otwartego i łatwo dostępnego. Po pierwsze, wrażenie otwartości niszczą nadmiernie rozbudowane sekwencje wejść. Ta, którą musi pokonać czytelnik zanim dotrze do pierwszego stanowiska bibliotekarza lub zbiorów, jest wyjątkowo długa - wchodząc z ulicy trzeba wejść po schodkach, pokonać podwójne drzwi i bramkę, następnie wejść zamkniętą klatką schodową na pierwsze piętro i przejść kolejne drzwi z holu do Wypożyczalni, co w sumie daje osiem różnych „przeszkód”. Ponadto podział wnętrza biblioteki jest bardzo wyraźny, nie tylko ze względu na strukturę wielopiętrowego gmachu, ale także na zastosowane rozwiązania: pierwsze piętro podzielono na kilka stref, a podział pionowy podkreślono przez zamkniętą klatkę schodową i umieszczenie magazynu zamkniętego na piątym piętrze - między czytelnią (niżej) i strefą rekreacyjną (wyżej). Podział przestrzeni złagodzono poprzez zastosowanie przeszklonych ścianek działowych, ale jedyną naprawdę otwartą częścią jest Czytelnia Główna. Większość tych problemów Książnica Podlaska odziedziczyła po organizacji przestrzennej Biblioteki Uniwersyteckiej, aczkolwiek obecnie wszystkie kondygnacje powyżej 
drugiego piętra są zamknięte dla czytelników, co tworzy może bardziej spójną, ale nie bardziej otwartą strukturę.

Dodatkowo, mimo iż budynek ma przeszkloną ścianę frontową, zastosowano szereg metod separacji wizualnej, odsuwających czytelnika od przechodnia. Po pierwsze, ściana frontowa jest cofnięta w podcień i oddzielona od ulicy klombami i schodami. Po drugie, we frontowych pomieszczeniach umieszczone są: księgarnia i sala wystawowa, a pomieszczenia przeznaczone dla czytelników znajdują się na pierwszym i drugim piętrze, więc czytelnik ma widok na ulicę, ale już „ulica nie ma widoku na czytelnika”. A przecież biblioteka (zwłaszcza publiczna) powinna starać się wyjść do potencjalnego czytelnika, nawiązać z nim dialog jeszcze zanim przekroczy jej drzwi i zachęcić do odwiedzin. Dzięki swojej konstrukcji (z przeszkloną ścianą frontową) i lokalizacji w centrum, dawny gmach BU ma potencjał, żeby taką więź z przechodniem nawiązać, wzorem np. Centrum Informacji Naukowej i Biblioteki Akademickiej w Katowicach, ale tego potencjału nie wykorzystuje. Rozwiązanie to było dyskusyjne już w przypadku Biblioteki Uniwersyteckiej (odcinającej się od, jakby nie było, obcego środowiska), a w przypadku biblioteki publicznej jest to już jednoznaczny błąd.

Gdy gmach mieścił Bibliotekę Uniwersytecką, pełnił kilka funkcji wykraczających poza podstawowe zadania biblioteki. Znalazła się tu księgarnia, sala konferencyjna oraz sala wystawowa, której znaczenie podkreślono przez umieszczenie jej na parterze (blisko wejścia), zaznaczając przy tym jej odrębny charakter przez oddzielenie jej od holu wejściowego. W późniejszym okresie w budynku umieszczono również salę Senatu UwB. Poza tą ostatnią, budynek zachował obecnie wszystkie te funkcje. Najbliżej wejścia znajduje się wspomniana sala wystawowa i szatnia. Oprócz nich na parterze umieszczono też gabinety dyrekcji, a za czasów funkcjonowania w gmachu BU, także dział wypożyczeń międzybibliotecznych.

Styl i estetykę wyposażenia i wystroju biblioteki można określić jako nowoczesne i pragmatyczne. W przypadku Biblioteki Uniwersyteckiej można też było mówić o silnej standaryzacji, od której na szczęście odeszła Książnica Podlaska. Wystrój ociepla obecność roślin doniczkowych. Mimo zastosowania pewnych rozwiązań wskazujących na hierarchiczny charakter kultury organizacyjnej (np. rozbudowana sekwencja wejść, położenie gabinetu dyrektora przy wejściu, czy umieszczenie w budynku sali senatu), ogólnie organizacja przestrzenna gmachu Biblioteki Uniwersyteckiej im. Jerzego Giedroycia w Białymstoku wskazywała raczej na mały dystans władzy, zgodnie z zaleceniami literatury przedmiotu. Po przejęciu budynku przez Książnicę Podlaską nie dokonano znaczących zmian, zachowano 
więc ogólną „orientację” budynku. Należy jednak zaznaczyć, że jego główne mankamenty (nadmierną separację od świata zewnętrznego) należy uznać za większy problem w przypadku biblioteki publicznej niż w przypadku biblioteki akademickiej.

\section{Podsumowanie}

$\mathrm{Na}$ koniec można by zapytać, która $\mathrm{z}$ dwóch omawianych bibliotek lepiej wykorzystuje analizowany budynek. Na to pytanie nie ma jednoznacznej odpowiedzi. Na pierwszy rzut oka wydaje się, że Książnica Podlaska wykonała krok wstecz, rezygnując z wolnego dostępu i nie wykorzystując okazji, żeby otworzyć się na świat. Jednocześnie jednak dokonano wielu drobnych, ale pozytywnych zmian. Nie można więc powiedzieć, że któraś z dwóch omawianych bibliotek wykorzystuje budynek jednoznacznie lepiej. Pokazuje to też, że użycie zaproponowanego tu arkusza obserwacji pozwala uniknąć powierzchownych ocen.

Podsumowując, należy podkreślić przede wszystkim zalety omawianego gmachu, który jest nowoczesny, świetnie zlokalizowany i w większości zbudowany zgodnie z zasadami budownictwa bibliotecznego. Dla obu bibliotek przeprowadzka $\mathrm{z}$ wcześniejszej lokalizacji była niewątpliwym postępem. Jednocześnie nie można zignorować wad budynku, który wydaje się „bać” czytelnika - separując go od zasobów biblioteki na różne sposoby. Książnica Podlaska, po przejęciu budynku dokonała drobnych zmian zmierzających we właściwym kierunku, ale też zmianom tym towarzyszyła rezygnacja $z$ wolnego dostępu. Jednakże najpoważniejszym zarzutem, jaki można postawić zmianom wprowadzonym przez Książnicę Podlaską jest, że nie poszły one dostatecznie daleko, szczególnie ze względu na inny niż w przypadku biblioteki akademickiej charakter i cele Książnicy.

\section{Bibliografia}

1. Biblioteka Uniwersytecka im. Jerzego Giedroycia w Białymstoku. Misja. Tryb dostępu: https://bg.uwb.edu.pl/bu/o-bibliotece/przewodnik-po-bibliotece/826-misja [24 lutego 2017].

2. Biblioteka Uniwersytecka w Poznaniu. Misja Biblioteki Uniwersyteckiej. Tryb dostępu: http://lib.amu.edu.pl/misja-biblioteki/ [24 lutego 2017].

3. Biblioteka Uniwersytecka we Wrocławiu. O Bibliotece - Misja Biblioteki. Tryb dostępu: http://www.bu.uni.wroc.pl/o-bibliotece/organizacja-biblioteki-misja [24 lutego 2017]. 
4. Bogusz A.: Image nowo powstającej biblioteki w oparciu o kulture organizacyjna na przykładzie Biblioteki Politechniki Krakowskiej. W: Kultura organizacyjna w bibliotece. Red. H. Brzezińska-Stec. Białystok 2008, s. 361-373.

5. Dzięcioł A.: The Communicative Approach in Foreign Language Teaching and the Negative Stereotype of the Polish Student. W: Us and Them - Them and Us. Eds. A. Gonerko-Frej et al. Aachen 2011, s. 605-620.

6. Gaziński R., Różycka M.: Adaptacja obiektów historycznych na potrzeby biblioteki naukowej na przykładzie Biblioteki Głównej Uniwersytetu Szczecińskiego. W: Kultura organizacyjna w bibliotece. Red. H. Brzezińska-Stec. Białystok 2008, s. 413-426.

7. Jaskowska B.: Jak badać kulturę organizacyjna $w$ bibliotece akademickiej? W: Kultura organizacyjna w bibliotece. Red. H. Brzezińska-Stec. Białystok 2008, s. 25-42.

8. Kultura organizacyjna w bibliotece. Red. H. Brzezińska-Stec. Białystok 2008.

9. Littlewood W.: Students' attitudes to classroom English learning. „Language Teaching Research" 2001, 5(1), s. 3-28.

10. McDonald A.: The Ten Commandments revisited: the Qualities of Good Library Space. „Liber Quarterly” Vol. 16, nr 2 (2006). Tryb dostępu: http://liber.library. uu.nl/index.php/lq/article/view/7840/8010 [24 lutego 2017].

11. Pawłowska M.: Wpływ architektury $i$ aranzacji przestrzennej bibliotek na jej kulture organizacyjna. W: Kultura organizacyjna w bibliotece. Red. H. Brzezińska-Stec. Białystok 2008, s. 440-456.

12. Pędich M.: Biblioteka w pięciu wymiarach. W: Kultura organizacyjna w bibliotece. Red. H. Brzezińska-Stec. Białystok 2008, s. 427-439.

13. Pędich M.: Individualism and Collectivism in Library Architecture. An Analysis of Selected New Library Buildings in the Former East Germany. „Zarządzanie Biblioteką: Library Management” Nr 1(10) (2018), s. 118-142.

14. Pędich M.: Kultura narodowa i organizacyjna w przestrzeni bibliotek. Studium porównawcze na przykładzie bibliotek akademickich $w$ Polsce i Niemczech oddanych do użytku po 1989 r. Toruń 2017. [rozprawa doktorska].

15. Pędich M.: Siedem wymiarów biblioteki. W: Język a komunikacja 25: Słowo w dialogu międzykulturowym. Red. W. Chłopicki, M. Jodłowiec. Kraków 2010, s. 47-53.

16. Szczygłowska L.: Nowa biblioteka - nowa przestrzeń - nowe możliwości - nowe wyzwania. W: Kultura organizacyjna $w$ bibliotece. Red. H. Brzezińska-Stec. Białystok 2008, s. 457-474.

17. Zybert E. B.: Kultura organizacyjna w bibliotekach. Warszawa 2004. 